\title{
Effect of vardenafil on diabetic foot ulcer (DFU) in rats
}

\section{Hany Anwer*, Waleed Barakat, Mona F Mahmoud}

Department of Pharmacology and Toxicology, Faculty of Pharmacy, Zagazig University, Zagazig, Egypt.

* Corresponding author e-mail: hany_anwer2k@yahoo.com

\begin{abstract}
The present study was designed to investigate the possible effect of vardenafil phosphodiesterase-5 inhibitor on diabetic foot ulcer induced in rats and the underlying mechanism(s).

Streptozotocin -induced diabetic rats were treated with the phosphodiesterase-5 inhibitor, vardenafil, for 8 weeks starting on day 15 after Streptozotocin injection. After 4 weeks of treatment, a wound of fixed size was induced in the dorsal surface of right foot and wound size measured every 3 days. Behavior tests (foot print and hotplate test) were performed every 2 weeks. At the end of the study, animals were euthanized, body weight, serum insulin, glucose, glycated haemoglobin, interlukin-6, adiponectin and hematoxylin and eosin stained sections were investigated.

Diabetes resulted in delayed wound healing, elevated blood glucose, HbA1c, IL-6, reduced serum insulin and adiponectin, treatment with vardenafil lead to improvement in all tested parameters.

In conclusion, the phosphodiesterase 5 inhibitor vardenafil can be used for the treatment of diabetic foot ulcer (DFU) since it is already used for other indications. Further studies are required to confirm its effects either alone or combined with other antidiabetic therapies.
\end{abstract}

Keywords: Vasodilators, NO, Phosphodiesterase, Diabetic foot ulcer, adiponectin, IL-6, wound healing.

\section{INTRODUCTION}

Diabetes mellitus is an endocrine disorder resulting from inadequate insulin release or insulin insensitivity (Wrighten et al., 2009). the prevalence of diabetes worldwide was estimated to be $2.8 \%$ in 2000 and is expected to reach $4.4 \%$ in 2030 (Wild et al., 2004).

Diabetic vascular complications are currently the principle causes of morbidity and mortality in patients with type I and type II DM (Khan \& Chakrabarti, 2003).

Diabetic peripheral neuropathy (DPN) is the most prevalent complication of diabetes and often manifests as a distal, symmetric, sensorimotor neuropathy (Harati, 2007). Clinical symptoms associated with DPN involve poor gait and balance associated with large sensory fibers and abnormal cold and/or heat sensation associated with small sensory fibers. Chronic pain associated with diabetes is represented by hyperalgesia, allodynia, paresthesias, and spontaneous pain (Gooch \& Podwall, 2004;Edwards et al., 2008). Symptoms are described as tingling, "pins and needles," burning, itching, and an abnormal sensation to pain and temperature. Over time, these symptoms may advance from the toes to the foot and up the leg, and these symptoms may occur in the fingers and 
hands (Zochodne, 2007). When the nerve gets injured, the patient is at a higher risk of getting a minor injury without noticing it until it becomes an ulcer. The risk of developing foot ulcers in patients with sensory loss is increased up to seven-fold, compared to non-neuropathic patients with diabetes (Wild et al., 2004). Ulceration of the diabetic foot, either neuropathic or ischemic, does not occur spontaneously. It usually follows some form of extrinsic or intrinsic trauma (Reiber et al., 1999).

Nitric oxide (NO) has beneficial effects on wound healing, including potentiation of the clotting process, scavenging of oxidative stress components, improvement of angiogenesis, promotion of endothelial cell proliferation, and tissue remodeling (Han et al., 2017) .

Several PDE5 inhibitors as vardenafil have been developed and used as therapeutic agents, as they increase cyclic nucleotide levels by blocking PDE function, enhancing NO-cGMP signalization (Peixoto \& Gomes, 2015)

The present study was designed to investigate the possible beneficial effect of vardenafil on the diabetic foot ulcer induced in rats.

\section{MATERIALS and METHODS}

\subsection{Animals}

Adult male Wistar albino rats $(150-200 \mathrm{~g})$ were used in this study. Animals were supplied from national research center (Dokki, Cairo, Egypt). Experimental design and animal handling procedures were according to the guidelines of the Ethical Committee of the Faculty of Pharmacy, Zagazig University, for Animal Use.

\subsection{Drugs}

Streptozotocin was supplied from (SigmaAldrich, Dorset, UK), vardenafil was supplied from Eva pharm (Egypt). The required dose of each drug was dissolved in distilled water just before use.

\subsection{Induction of diabetes}

Rats (150-200 g) were fasted for 12 hours, then received single intraperitoneal (i.p) injection of STZ $(50 \mathrm{mg} / \mathrm{kg})$ dissolved in ice cold distilled water immediately before use (Reed et al., 1999). Rats were given glucose $(10 \%)$ solution in the day following STZ injection to avoid acute hypoglycemia. Rats with non-fasting blood glucose level between 300 and $400 \mathrm{mg} / \mathrm{dl}$ were randomly distributed between experimental groups ( 8 animals each) in addition to control animals as follow; Control, Diabetic, Vardenafil-diabetic.

\subsection{Experimental design}

Vardenafil at $5 \mathrm{mg} / \mathrm{kg} /$ day was daily administered for 8 weeks by oral gavage after 2 weeks of STZ administration.

Behavior tests were performed for all experimental groups at 2, 4, 6 and 8 weeks of the study. On the 5th week of the study, a wound of fixed size $(5 \mathrm{~mm})$ was made in the dorsal surface of right foot. Initial wound size was measured on day 1 then every 3 days to the end of the study.

At the end of the study and $12 \mathrm{~h}$ after the last injection, blood was collected from the retro-orbital plexus and centrifuged (3000 $\left.\times \mathrm{g}, 4^{\circ} \mathrm{C}, 20 \mathrm{~min}\right)$ to separate serum that was divided into aliquots and stored at $-20^{\circ} \mathrm{C}$ for biochemical analysis. For each animal, the right foot was fixed in $10 \%$ phosphate buffered formalin solution for histopathological examination.

\subsection{Behavioral tests}

\subsubsection{Hot plat test:}

Acute thermal pain was modeled by the hot plate which is a method designed to measure thermal analgesia in rodents. The surface of a hot plate (model XH-2002 premiere slide warmer; Daigger,Vernon 
Hills, IL) was heated to achieve a constant temperature of $50( \pm 0.5){ }^{\circ} \mathrm{C}$, which was ascertained using a built-in digital thermometer. The time (in seconds) between the placement of the rats on the plate and the onset of shaking, paw licking, and jumping off the plate was recorded as the response latency. To avoid tissue damage, 50 seconds was set as the cut-off time after which the rats were returned to the cage, regardless of whether or not a response was observed (Bogo et al., 1981).

\subsubsection{The footprint test:}

The test was designed to measure latent motor deficit according to the method described by (Balkaya et al., 2013). Parameters that were measured using this test are stride length, gait base width, stride variability (forepaw/hindpaw overlap). For each step parameter, three values were measured from each run, excluding footprints made at the beginning and end of the run where the animal was initiating and finishing movement, respectively. The mean value of each set of three values was used in subsequent analysis.

\subsection{Wound induction}

Wound was induced after 4 weeks of treatment. On the day of wound induction (defined as day 0) each rat was anesthetized with an intraperitoneal injection of $50 \mathrm{mg} / \mathrm{kg}$ thiopental sodium. A rectangular pattern was marked on the dorsal surface of the foot using a flexible transparent plastic template, and then a layer of skin in full thickness with standard area of $2 \times 5 \mathrm{~mm}$ was removed and initial wound size was measured on day 1 then every 3 days to the end of the study (Lau $e t$ al., 2009).

\subsection{Histopathological examination}

The right foot was rapidly dissected out and fixed by immersion in 10\% phosphate buffered formalin solution at room temperature. For the histological examinations, paraffin-embedded tissue sections of foot were stained with hematoxylin and eosin (H\&E) according to the method described by (Takeo et al., 1989). Tissue sections were examined under light microscope at magnification power $\mathrm{x} 300$ and $\mathrm{x} 1200$.

\subsection{Biochemical analysis}

Serum insulin level was assayed by sandwich ELISA (Millipore, Cairo, Egypt) which uses microtiter plate coated with mouse monoclonal anti-rat insulin antibodies. Serum glucose was determined by glucose meter (Bionime $\mathrm{GmBH}$ ) using noble metal electrode strips. Glycated hemoglobin was measured using chromatographic spectrophotometric ion exchange BioSystems S.A. ${ }^{\circledR}$ kits (Costa Brava 30, Barcelona, Spain). Serum IL6 level was determined by enzyme-linked immunosorbent assay (ELISA) using IBLAMERICA rat IL-6 ELISA Kit. Serum adiponectin level was assayed by ELISA using CHEMICON $^{\circledR}$ rat adiponectin ELISA kit (Chemicon International, Temecula, CA, USA) that uses microtiter plate coated with polyclonal antibody-1 specific for rat adiponectin. The assays were performed in accordance with the manufacturer's protocol.

\subsection{Statistical analysis}

Statistical analysis was carried out using GraphPad Prism 5.0® software (Graphpad Software, La Jolla; CA; USA). Results were expressed as the mean \pm standard error of the mean (mean \pm SEM). One-way analysis of variance (ANOVA) was used for multiple comparison between groups followed by Newman-Keul's post hoc test with level of significance; $\mathrm{p}<0.05$. Two-way ANOVA followed by Bonferroni post hoc was used to compare statistical 
difference in behavioral experiments and wound healing.

\section{RESULTS}

\subsection{Effect of diabetes and treatment} with vardinafil on latency time in hotplate test:

The hot plate is a method designed to measure thermal analgesia in rodents.
Diabetes resulted in a significant decrease in hotplate latency time after 2, 4, 6 and 8 weeks compared to control group. While, administration of vardinafil to diabetic animals resulted in significant increase in hotplate latency compared to diabetic group (fig.1).

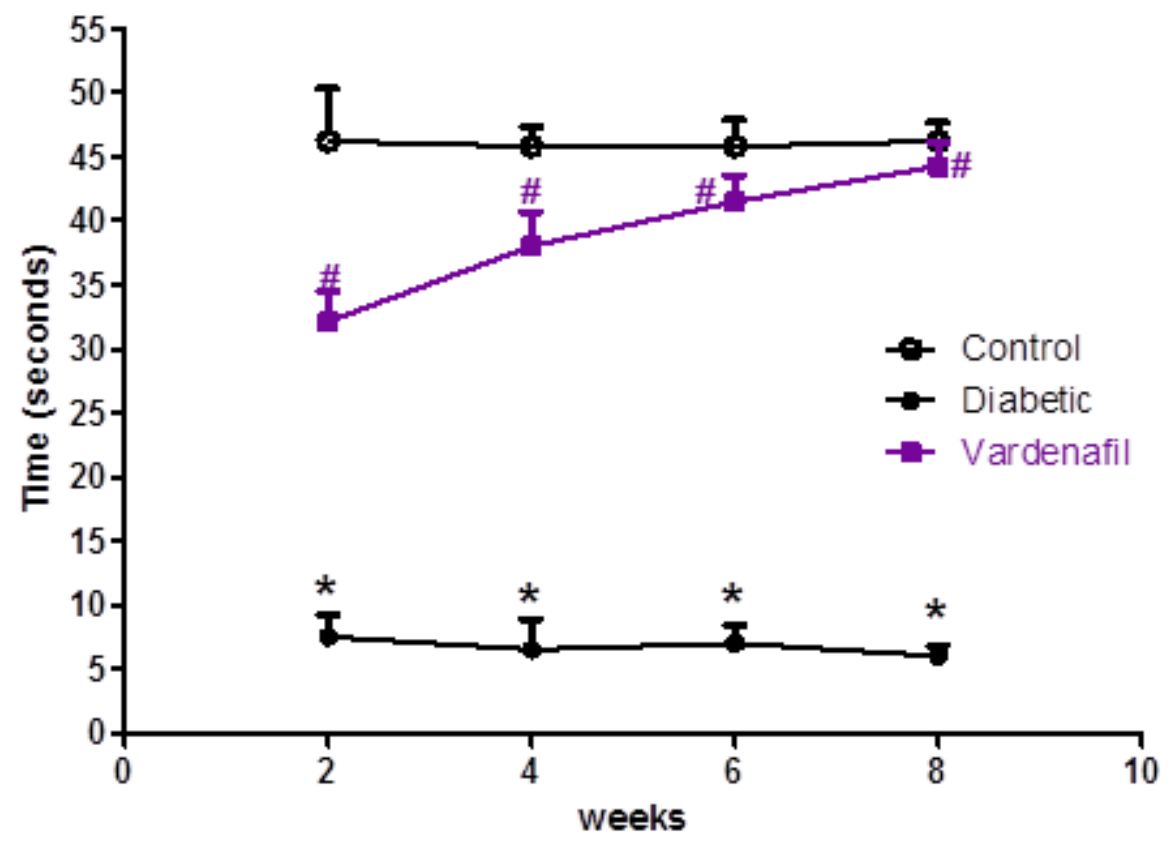

Fig. 1: Effect of vardenafil $\left(5 \mathrm{mg} \cdot \mathrm{kg}^{-1}\right)$ on latency time in hot plate test in diabetes.

\subsection{Effect of diabetes and treatment with vardinafil on foot print test parameters:}

Diabetes resulted in a significant decrease in gait base after 2, 4, 6 and 8 weeks of treatment compared to control group. While, administration of vardinafil to diabetic animals resulted in significant increase in gait base compared to diabetic group (fig. 2a).

In addition, diabetes resulted in a significant decrease in intrastep distance after 2, 4, 6 and 8 weeks compared to control group, while, administration of vardinafil to diabetic animals resulted in significant increase in intrastep distance compared to diabetic group (fig. 2b).
Diabetes also resulted in a significant decrease in left and right leg stride length after 2, 4, 6 and 8 weeks compared to control group and this was not changed following treatment with vardinafil (fig. $2 c \& d)$.

Diabetes resulted in a significant decrease in left leg stride variability after 2, 4, 6 and 8 weeks compared to control group, while, administration of vardinafil to diabetic animals resulted in significant increase in left leg stride variability compared to diabetic group (fig. 2e).

Diabetes resulted in a significant decrease in right leg stride variability after 2, 4, 6 and 8 weeks compared to control group, while, administration of vardinafil to 
Zagazig J. Pharm. Sci. June, 2018

Vol. 27, Issue 1, pp. 73-85

diabetic animals resulted in significant increase in right leg stride variability

a)

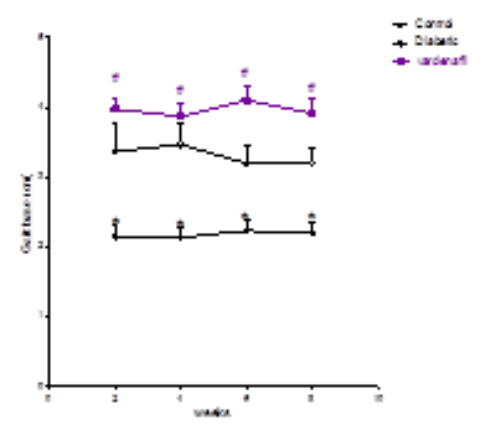

c)

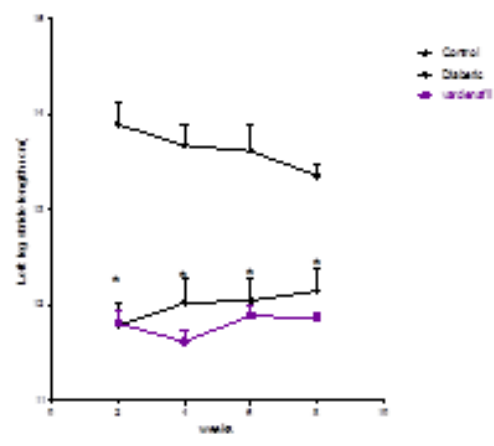

e)

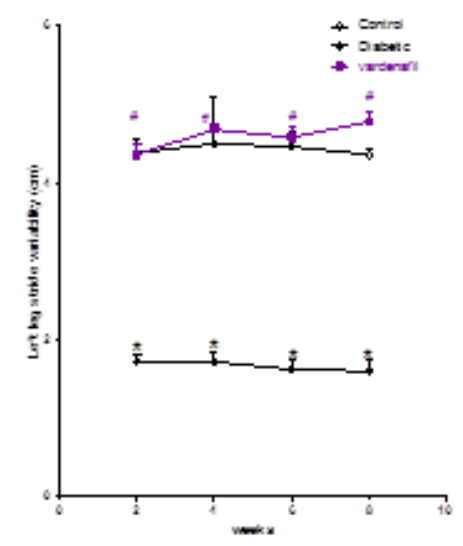

ISSN 1110-5089

ISSN (on-line) 2356_9786

compared to diabetic group (fig. 2f).

b)

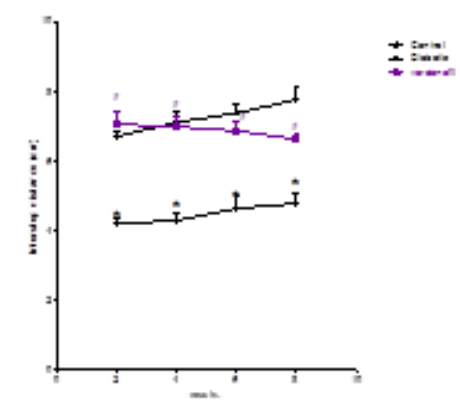

d)

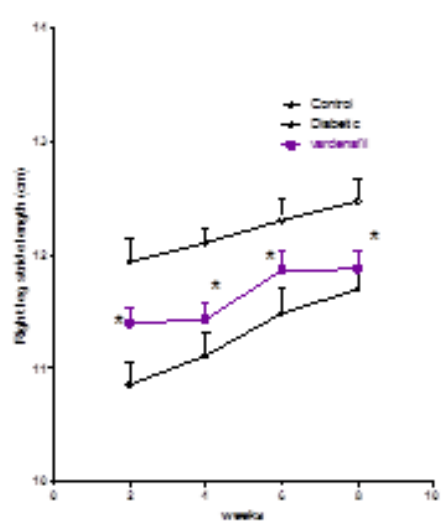

f)

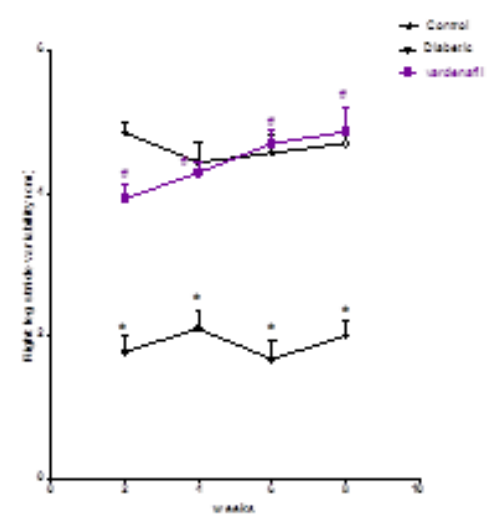

Fig. 2: effect of vardenafil $\left(5 \mathrm{mg} \cdot \mathrm{kg}^{-1}\right)$ on right leg stride length, left leg stride length, right leg stride variability, left leg stride variability, gait base and intra-step distance in diabetes.

\subsection{Effect of diabetes and treatment} with vardenafil on wound healing:

Diabetes resulted in delayed wound healing on days $5,9,13,17,21,25,29$ compared to control group. Improvement in wound healing was observed in diabetic animals treated with vardenafil compared to diabetic group (fig.3). 


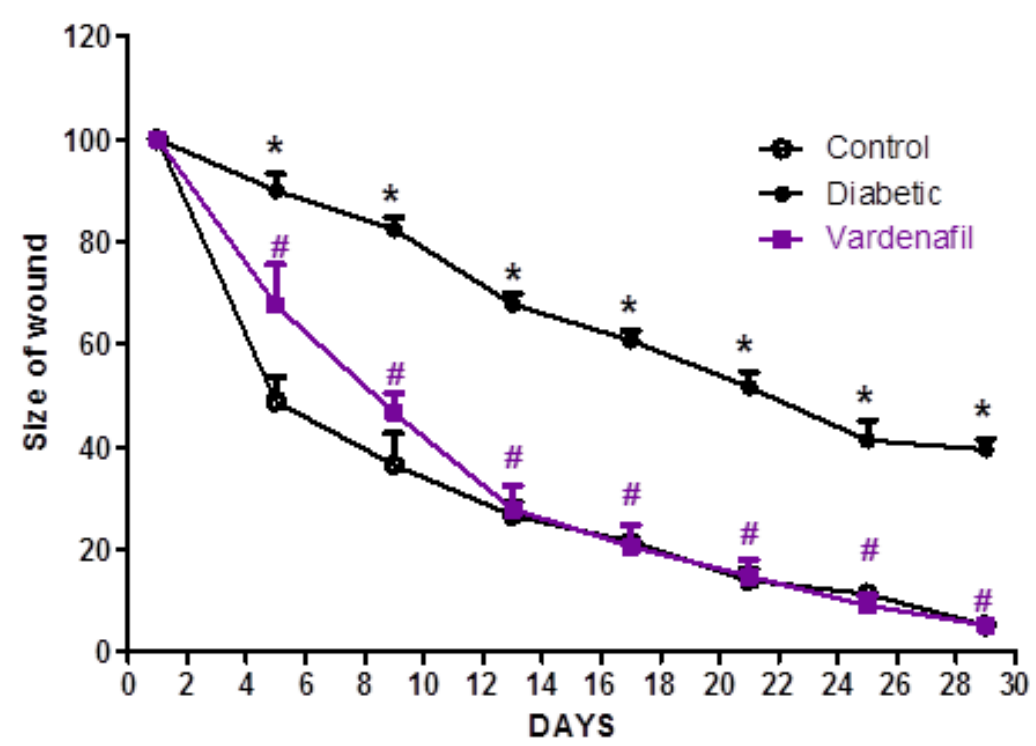

Fig. 3: effect of vardenafil $\left(5 \mathrm{mg} . \mathrm{kg}^{-1}\right)$ on wound healing in diabetes.

\subsection{Effect of diabetes and treatment with vardenafil on tissue histopathology:}

Figure 4 shows the effect of diabetes and treatment on tissue histopathology; a normal rat skin formed of normal epidermis and underlying dermis with absence of inflammatory cells and granulation tissue is shown in figure $4 a$, while diabetic rat skin after injury showed heavy aggregates of inflammatory cells surrounded by thin-walled vascular spaces (fig. 4b). Treatment with vardenafil showed granulation tissue in the dermis formed of numerous thin-walled vascular spaces containing red blood cells and surrounded by increased collagen bands (fig. 4c).

\subsection{Effect of diabetes and treatment} with vardenafil on body weight, blood glucose, glycated hemoglobin and insulin levels:

Diabetes resulted in a significant decrease in body weight compared to control group. While, administration of vardinafil to diabetic animals resulted in significant increase in body weight compared to diabetic group (fig. 5a).
Diabetes resulted in a significant increase in blood glucose compared to control group, diabetes also increased HBA1C compared to control group, On the other hand, diabetes resulted in a significant decrease in insulin level compared to control group, While, administration of vardinafil to diabetic animals has no significant effect on blood glucose, glycated hemoglobin or insulin levels (fig. $5 b, c, d)$.

\subsection{Effect of diabetes and treatment} with vardenafil on adiponectine and IL6 level:

Diabetes resulted in a significant decrease in serum adiponectin level compared to control group, while, administration of vardinafil to diabetic animals resulted in significant increase in serum adiponectin level compared to diabetic group (fig.6a).

On the other hand, diabetes resulted in a significant increase in IL-6 level compared to control group, while, administration of vardinafil to diabetic animals resulted in significant decrease in IL-6 level compared to diabetic group (fig. 6b). 


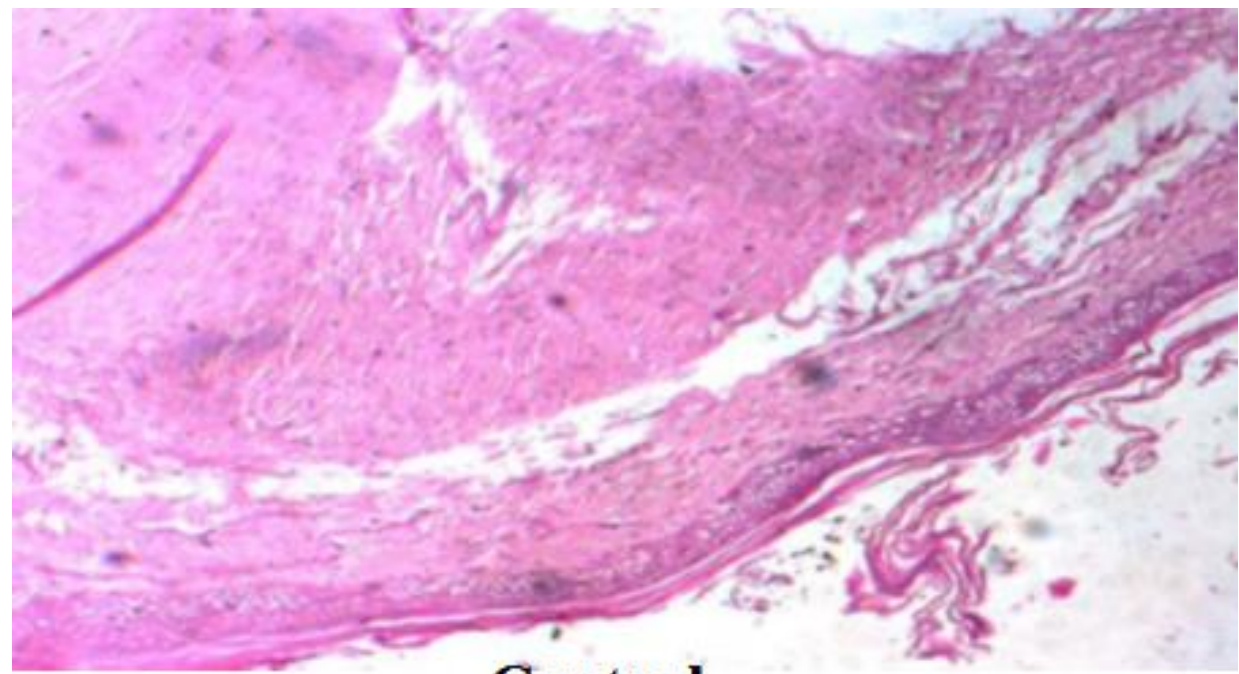

\section{Control}

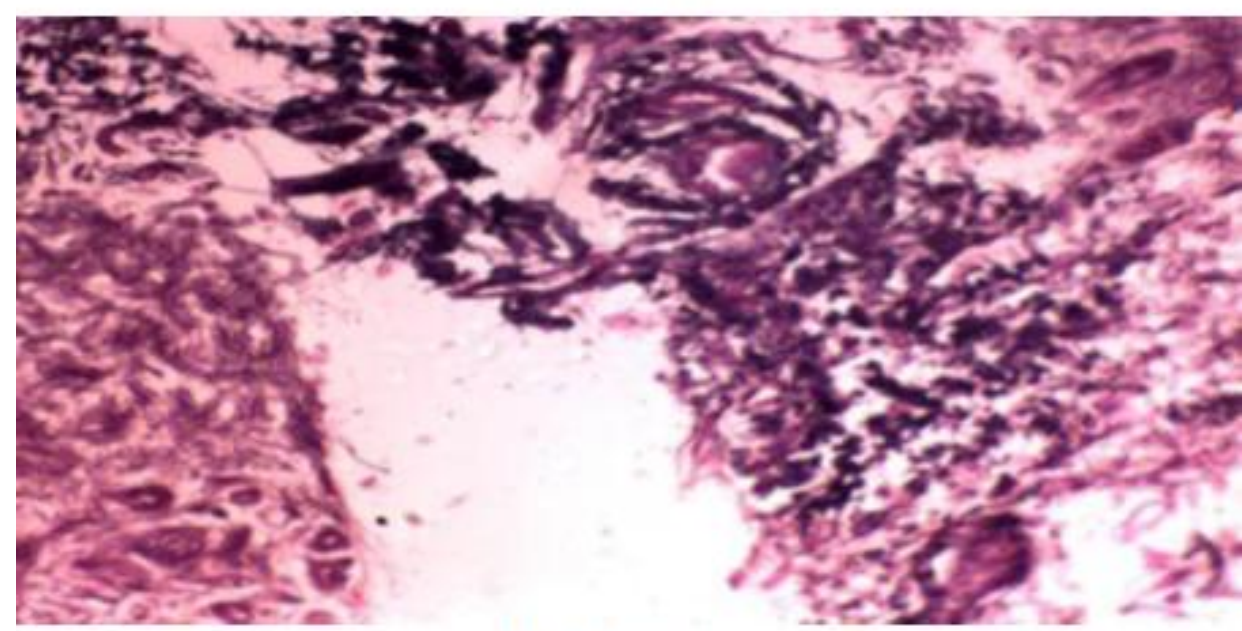

Diabetic

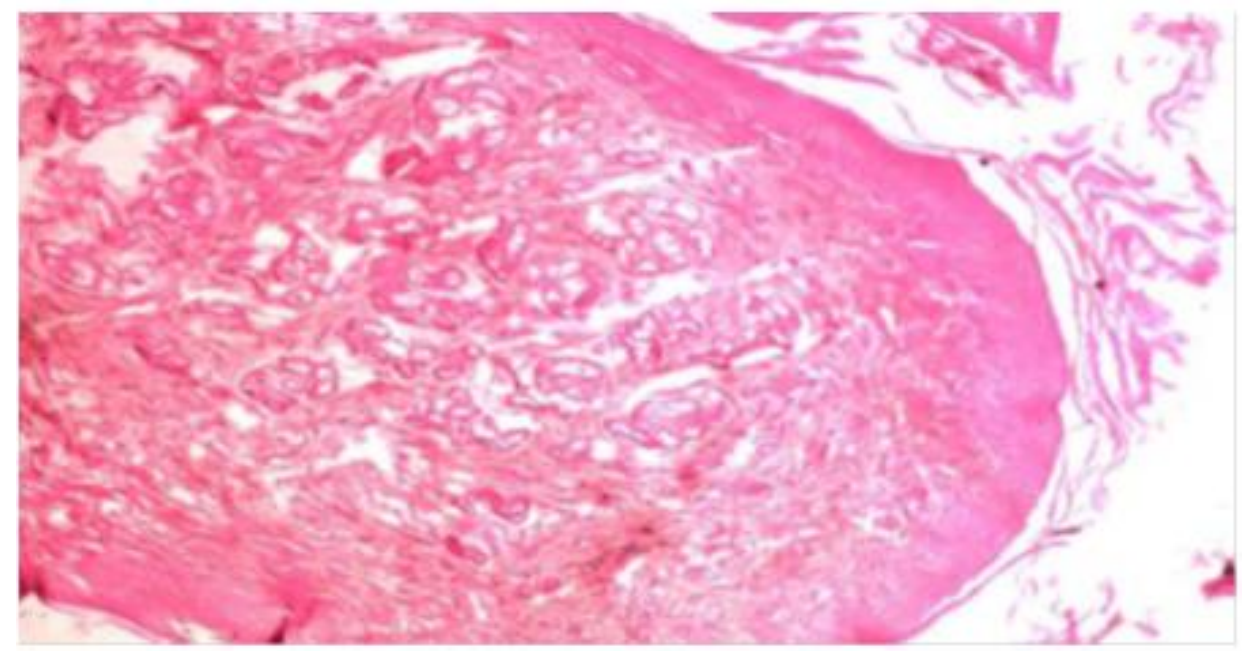

Vardenafil

Fig. 4: effect of vardenafil $\left(5 \mathrm{mg} \cdot \mathrm{kg}^{-1}\right)$ on tissue histopathology in diabetes. 
a)

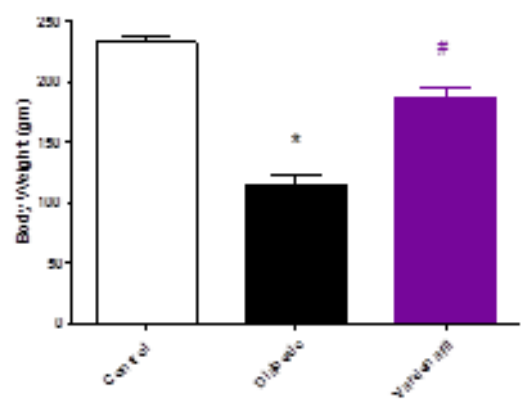

c)

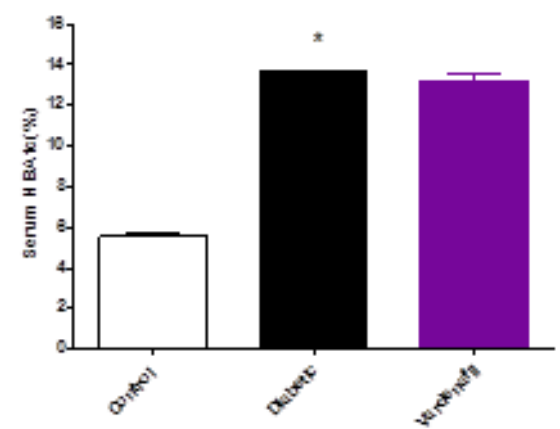

b)

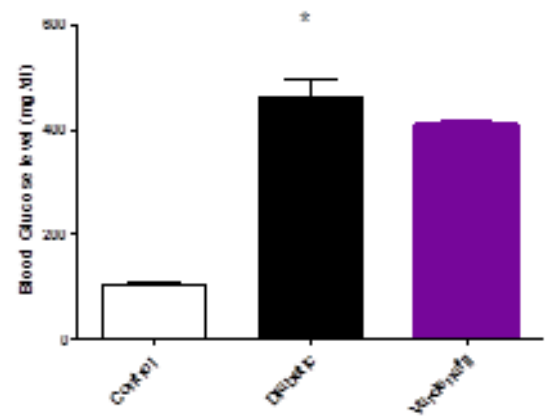

d)

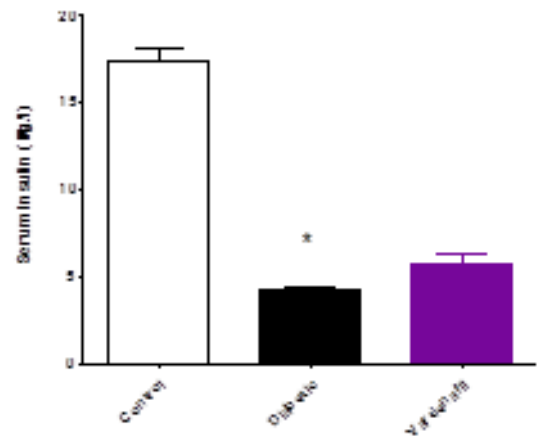

Fig. 5: effect of vardenafil $\left(5 \mathrm{mg}^{-\mathrm{kg}^{-1}}\right)$ on body weight, blood glucose, serum insulin, HBA1C in diabetes.

a)

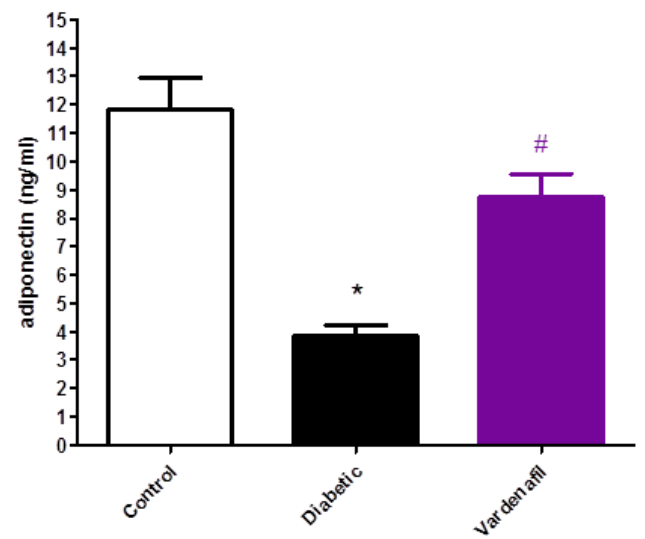

b)

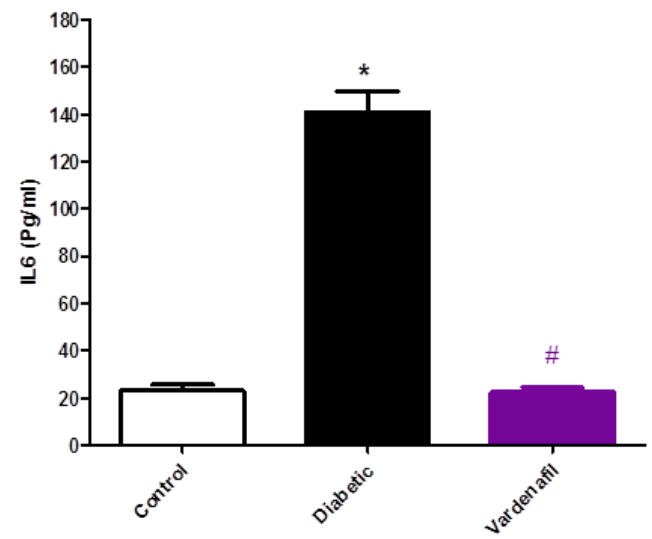

Fig. 6: effect of vardenafil $\left(5 \mathrm{mg} \cdot \mathrm{kg}^{-1}\right)$ on adiponectin and interleukin 6 (IL6) in diabetes.

\section{DISCUSSION}

The current study is the first to report on the potential protective effect of vardenafil on wound healing of diabetic foot ulceration induced in rats.
The increased risk of chronic ulcer formation stems from disruption of the complex process of wound healing by the pathophysiological abnormalities associated with diabetes (Andrews et al., 2015). In present study, diabetes resulted 
in poor wound healing which is in agreement with the study of (Gulcan et al., 2012) which demonstrated the negative impact of diabetes on healing rate of streptozotocin-induced diabetic ulcer on rats skin. Treatment with vardenafil accelerated the healing rate and decreased the ulcer area till it became as equal as control group.

Diabetes affects the three phases of wound healing; the inflammatory phase through compromising the immune system, the proliferative phase through suppression of collagen deposition and formation of new vessels (angiogenesis). and the remodeling phase in which reorganization of collagen occurs to restore the tissue structural integrity (Wuyts et al., 2013). In the present study, diabetes caused delayed healing in most of the animals. Furthermore, the skin of healed ulcers appeared to be abnormal as was seen with light microscopic examination. There was also a significant increase in wound surface area and significant decrease in each of the epidermal thickness, colour area percentage of collagen and vascular area density compared with the control groups.. Previous studies have reported diminished proliferative capacity, abnormal morphology of fibroblasts derived from diabetic ulcers and impaired fibroblast migration to wound in diabetic patients (Sugimoto et al., 2013). Another important impairment to healing of diabetic wound is lack of migration of keratinocytes and fibroblasts (Sugimoto $e t$ al., 2013); this would result in reduction of collagen deposition and delay in wound healing. Impaired angiogenesis is a clinically significant problem in diabetic patients (Bitto et al., 2013), and clinical trials indicate that therapies designed to improve vascularization can improve the outcomes in patients with severe skin wounds and diabetic ulcers (Luo et al., 2004). In the present study, the use of vardenafil revealed marked improvement and healing of wounds in most of the animals. Light microscopic examination revealed that the newly formed skin was of normal appearance. There was also a significant decrease in wound surface area in addition to the significant increase in all other parameters (epidermal thickness, colour area percentage of collagen, vascular area density) compared with diabetic group.

Experimental multiple low-doses streptozotocin (MLD-STZ)-induced diabetes is characterized by extreme insulin deficiency as a result of a decrease in the number of functional $\beta$-cells (Bellenger et al., 2011). The mechanism by which STZ selectively destroys pancreatic $\beta$-cells is controversial (Otto et al., 2011a). In present study, a single intraperitoneal dose of STZ $(50 \mathrm{mg} / \mathrm{kg})$ developed significant increase in blood glucose level and significant decrease in serum insulin level. Treatment with vardenafil improved hyperglycemia and insulin level but the difference was not significant compared with diabetic group. Painful diabetic peripheral neuropathy (PDPN) is a debilitating condition and has been shown to affect approximately onequarter of patients with type 2 diabetes mellitus (Malik et al., 2017). Painful DPN significantly affects multiple measures of quality of life and is highly associated with depression, anxiety, and sleep disturbances (Rosenberg \& Watson, 2015). In the present study, diabetes increased thermal hyperalgesia in hot 
plate test as shown previously (Otto et al., 2011b). Treatment with vardenafil caused a significant increase in the time required for the animal to jump outside the cylinder indicating improved pain perception which suggests prevention of nerve damage associated with diabetic neuropathy.

Adaptations in gait and level of walking activity were identified to affect the plantar pressure distribution and ultimately the risk of ulceration to the surviving foot (Kanade et al., 2006). Footprint test is designed to measure gait disturbances (Broom et al., 2017). In the present study, diabetes was associated with significant change in gait parameters (intrastep distance, stride length, stride variability, gait base). Vardenafil administration caused significant improvement in intrastep distance, stride variability, gait base but had no effect on stride length compared to diabetic group. Interleukin-6 (IL-6) is a proinflammatory cytokine secreted by immune cells, adipose tissue and muscles, and is able to accelerate or inhibit the inflammatory processes. Recently, several prospective studies have associated increased plasma IL-6 levels with a higher risk of type 2 diabetes. These data suggest that IL6 is an appealing candidate gene for type 2 diabetes (Qi et al., 2006). Adiponectin, synthesized by white adipose tissue improves insulin sensitivity and exhibits anti-atherogenic, anti-inflammatory and anti-diabetic properties (Malli et al., 2011). In the present study, diabetes resulted in raised level of IL6 and low level of anti-inflammatory adiponectin. This is in agreement with a previous study which demonstrated that diabetic subjects with diabetic foot showed higher IL-6 and lower adiponectin plasma levels in comparison with diabetics without diabetic foot (Tuttolomondo et al., 2010). Vardenafil administration resulted in significant increase in serum adiponectin level and significant decrease in IL-6 level compared to diabetic animals.

In conclusion, our results have shown that vardenafil ameliorates diabetic foot ulceration induced in rats through its anti-inflammatory action. These actions were evidenced by suppression of diabetic ulcerative process, improved pain sensation and improvement in wound healing. Since the tested drug is already used clinically, so it could be safely included in diabetic treatment schedule either alone or with current antidiabetic therapies after suitable clinical trials are conducted.

\section{REFERENCES}

Andrews, KL, Houdek, MT \& Kiemele, LJ. (2015). Wound management of chronic diabetic foot ulcers: From the basics to regenerative medicine. Prosthetics and Orthotics International, 39, 29-39.

Balkaya, M, ber, JM, Rex, A \& Endres, M. (2013). Assessing Post-Stroke Behavior in Mouse Models of Focal Ischemia. Journal of Cerebral Blood Flow and Metabolism, 33, 330-338.

Bellenger, J, Bellenger, S, Bataille, A, Massey, KA, Nicolaou, A, Rialland, M, Tessier, C, Kang, JX \& Narce, M. (2011). High Pancreatic n-3 Fatty Acids Prevent STZ-Induced Diabetes in Fat-1 Mice: Inflammatory Pathway Inhibition. Diabetes, 60, 10901099.

Bitto, A, Irrera, N, Minutoli, L, Calo, M, Lo Cascio, P, Caccia, P, Pizzino, G, Pallio, G, Micali, A, Vaccaro, 
M, Saitta, A 'Squadrito, F \& Altavilla, D. (2013). Relaxin improves multiple markers of wound healing and ameliorates the disturbed healing pattern of genetically diabetic mice. Clinical Science, 125, 575-585.

Bogo, V, Hill, TA \& Young, RW. (1981). Comparison of accelerod and rotarod sensitivity in detecting ethanol- and acrylamide-induced performance decrement in rats: review of experimental considerations of rotating rod systems. Neurotoxicology, 2, 765787.

Broom, L, Ellison, BA, Worley, A, Wagenaar, L, S $\boldsymbol{\text { II }}$ rberg, E, Ashton, C, Bennett, DA, Buchman, AS, Saper, CB, Shih, LC, Hausdorff, JM \& VanderHorst, VG. (2017). A translational approach to capture gait signatures of neurological disorders in mice and humans. Sci Rep, 7.

Edwards, JL, Vincent, AM, Cheng, HT \& Feldman, EL. (2008). Diabetic neuropathy: mechanisms to management. Pharmacol Ther, 120, 1-34.

Gooch, C \& Podwall, D. (2004). The diabetic neuropathies. Neurologist, 10, 311-322.

Gulcan, E, Kucuk, A, Cayci, K, Tosun, M, Emre, H, Koral, L ،Aktan, Y \& Avsar, U. (2012). Topical effects of nebivolol on wounds in diabetic rats. Eur J Pharm Sci, 47, 451455.

Han, X, Deng, Y, Yu, J, Sun, Y, Ren, G, Cai, J, Zhu, J \& Jiang, G. (2017). Acarbose Accelerates Wound Healing via Akt/eNOS Signaling in $\mathrm{db} / \mathrm{db}$ Mice. Oxidative medicine and cellular longevity, 2017.

Harati, Y. (2007). Diabetic neuropathies: unanswered questions. Neurol Clin, 25, 303-317.

Kanade, RV, van Deursen, RW, Harding, K \& Price, P. (2006).
Walking performance in people with diabetic neuropathy: benefits and threats. Diabetologia, 49, 1747-1754.

Khan, ZA \& Chakrabarti, S. (2003). Endothelins in chronic diabetic complications. Can J Physiol Pharmacol, 81, 622-634.

Lau, TW, Lam, FF, Lau, KM, Chan, YW, Lee, KM, Sahota, DS, Ho, YY, Fung, KP, Leung, PC \& Lau, CB. (2009). Pharmacological investigation on the wound healing effects of Radix Rehmanniae in an animal model of diabetic foot ulcer. $J$ Ethnopharmacol, 123, 155-162.

Luo, JD, Wang, YY, Fu, WL, Wu, J \& Chen, AF. (2004). Gene Therapy of Endothelial Nitric Oxide Synthase and Manganese Superoxide Dismutase Restores Delayed Wound Healing in Type 1 Diabetic Mice. Circulation, 110, 2484-2493.

Malik, RA, Aldinc, E, Chan, SP, Deerochanawong, C, Hwu, CM ، Rosales, RL, Yeung, CY, Fujii, K \& Parsons, B. (2017). Perceptions of Painful Diabetic Peripheral Neuropathy in South-East Asia: Results from Patient and Physician Surveys. Adv Ther, 34, 1426-1437.

Malli, F, Georgoulias, P, Varvara, V, Tsilioni, I 'Gourgoulianis, $\mathrm{K} \&$ Daniil, Z. (2011). Leptin and adiponectin levels in idiopathic pulmonary fibrosis. European Respiratory Journal, 38, 653.

Otto, KJ, Wyse, BD, Cabot, PJ \& Smith, MT. (2011a). Insulin Implants Prevent the Temporal Development of Mechanical Allodynia and Opioid Hyposensitivity for 24-Wks in Streptozotocin (STZ)-Diabetic Wistar Rats. Pain Medicine, 12, 782-793.

Otto, KJ, Wyse, BD, Cabot, PJ \& Smith, MT. (2011b). Longitudinal Study 
of Painful Diabetic Neuropathy in the Zucker Diabetic Fatty Rat Model of Type 2 Diabetes: Impaired Basal G-Protein Activity Appears to Underpin Marked Morphine Hyposensitivity at 6 Months. Pain Medicine, 12, 437450.

Peixoto, CA \& Gomes, FS. (2015). The role of phosphodiesterase- 5 inhibitors in prostatic inflammation: a review. J Inflamm (Lond), 12.

Qi, L, van Dam, RM, Meigs, JB, Manson, JE, Hunter, D \& Hu, FB. (2006). Genetic variation in IL6 gene and type 2 diabetes: taggingSNP haplotype analysis in largescale case-control study and metaanalysis. Human Molecular Genetics, 15, 1914-1920.

Reed, MJ, Meszaros, K, Entes, LJ, Claypool, MD, Pinkett, JG, Brignetti, D, Luo, J, Khandwala, A \& Reaven, GM. (1999). Effect of masoprocol on carbohydrate and lipid metabolism in a rat model of Type II diabetes. Diabetologia, 42, 102-106.

Reiber, GE, Vileikyte, L, Boyko, EJ, del Aguila, M, Smith, DG, Lavery, LA \& Boulton, AJ. (1999). Causal pathways for incident lowerextremity ulcers in patients with diabetes from two settings. Diabetes Care, 22, 157-162.

Rosenberg, CJ \& Watson, JC. (2015). Treatment of painful diabetic peripheral neuropathy. Prosthetics and Orthotics International, 39, 17-28.

Sugimoto, T, Huang, L, Minematsu, T, Yamamoto, Y, Asada, M, Nakagami, G, Akase, T, Nagase, T, Oe, M, Mori, T \& Sanada, H. (2013). Impaired Aquaporin 3 Expression in Reepithelialization of Cutaneous Wound Healing in the Diabetic Rat. Biological
Research For Nursing, 15, 347355.

Takeo, S, Anan, M, Fujioka, K, Kajihara, T, Hiraga, S ‘Miyake, K, Tanonaka, K, Minematsu, R, Mori, H \& Taniguchi, Y. (1989). Functional changes of aorta with massive accumulation of calcium. Atherosclerosis, 77, 175-181.

Tuttolomondo, A, La Placa, S, Di Raimondo, D, Bellia, C, Caruso, A, Lo Sasso, B, Guercio, G, Diana, G, Ciaccio, M, Licata, G \& Pinto, A. (2010). Adiponectin, resistin and IL-6 plasma levels in subjects with diabetic foot and possible correlations with clinical variables and cardiovascular comorbidity. Cardiovasc Diabetol, 9 , 50.

Wild, S, Roglic, G, Green, A, Sicree, R \& King, H. (2004). Global Prevalence of Diabetes: Estimates for the year 2000 and projections for 2030. Diabetes Care, 27, 10471053.

Wrighten, SA, Piroli, GG, Grillo, CA \& Reagan, LP. (2009). A look inside the diabetic brain: Contributors to diabetes-induced brain aging. Biochim Biophys Acta, 1792, 444453.

Wuyts, WA, Agostini, C, Antoniou, KM, Bouros, D, Chambers, RC, Cottin, V, Egan, JJ, Lambrecht, BN, Lories, R, Parfrey, H, Prasse, A, Robalo-Cordeiro 'C, Verbeken, E, Verschakelen, JA, Wells, AU \& Verleden, GM. (2013). The pathogenesis of pulmonary fibrosis: a moving target. European Respiratory Journal, 41, 1207-1218.

Zochodne, DW. (2007). Diabetes mellitus and the peripheral nervous system: manifestations and mechanisms. Muscle Nerve, 36, 144-166. 


\section{تأثير فاردينافيل على قرحة القدم السكري في الفئران \\ هاني انور، وليد بركات، مني فؤاد

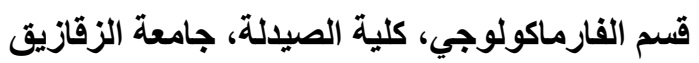

تم تصميم الدر اسة الحالية للتحقيق في التأثير المحتمل للفاردينافيل (PDE5i) على قرحة القدم السكري الدستحث في الفئران و الآلية (الآليات) الأساسية.

تم علاج الجرذان المصابة بداء السكري من STZ بو اسطة فاردينافيل مثبط

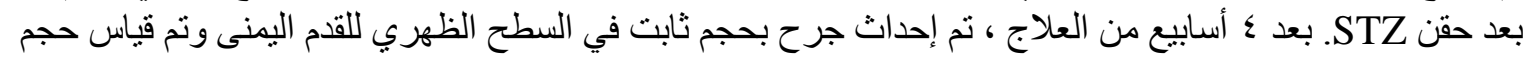

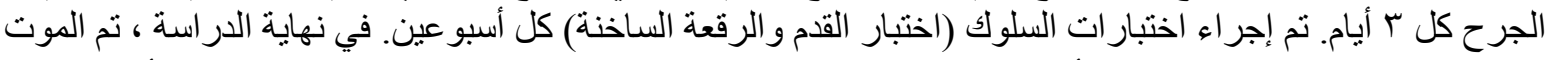

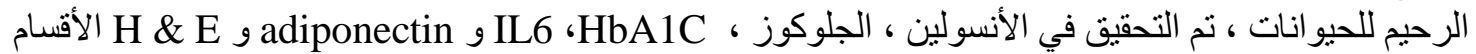
الملطخة.

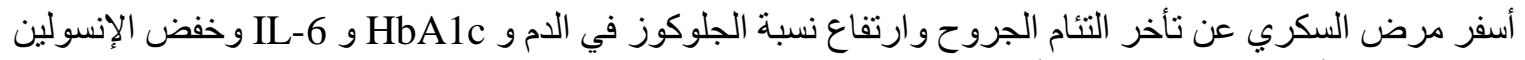
في المصل والأديبونيكتين ، في حين أن العلاج باستخدام علاج الحالة يؤدي إلى تحسن في جميع المعلمات المئ المختبرة. في الختام ، يمكن استخدام فاردينافيل مثبط 5 phosphodiesterase لعلاج قرحة القدم السكري لأنه يستخدم بالفعل

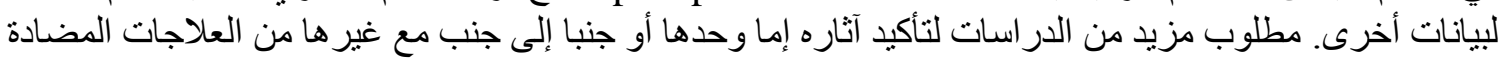
لمرض السكر. 